\title{
SisCuentos: Herramienta de apoyo para el aprendizaje de Compresión y Lectura para Niñas y Niños de Primer Grado de Primaria
}

\section{SisCuentos: Support tool for learning Compression and Reading for Girls and First Grade Primary School}

PÉREZ-VÁZQUEZ, Jenner†* \& MENDOZA-ZUÑIGA, Armando

Universidad Tecnológica del Sur del Estado de México

ID $1^{\text {er }}$ Autor: Jenner. Pérez-Vázquez, / ORC ID: 0000-0003-2475-6745, CVU CONACYT ID: 999003

ID $1^{\mathrm{er}}$ Coautor: Armando, Mendoza-Zuñiga / ORC ID: 0000-0002-5091-6135, CVU CONACYT ID: 548045

DOI: $10.35429 / J E S C .2019 .10 .3 .20 .26$

Recibido: 02 de Octubre, 2019; Aceptado 14 de Noviembre, 2019

\begin{abstract}
Resumen
En la actualidad las niñas y niños gestionan su propio aprendizaje, por lo tanto, nunca es el aprendizaje tan grande como cuando un docente está presente, ya que es el encargado de mediar, trasladar y traducir cada estímulo a las niñas y niños. Dentro de esta investigación se destaca el objetivo general para Desarrollar un Herramienta de apoyo para aprendizaje de Compresión y Lectura para Niñas y Niños de Primer Grado de Primaria de la Escuela General Lázaro Cárdenas de Tejupilco, Estado de México. La metodología utilizada está basada en la investigación. "Aplicar en la práctica los aprendizajes logrados para conseguir la trasformación de la práctica misma y la de los sujetos motivos de estudio". (Barabtarlo Y Zedansky, 2002) .En conclusión, se logró un resultado positivo donde los estudiantes fueron capaces de desarrollar y mejorar la Comprensión Lectora, además que los cuentos no sólo promueven el acceso a los contenidos de la cultura, los conocimientos, los valores, sino que, ponen en movimiento importantes mecanismos vinculados con el desarrollo cognitivo, el lingüístico y la creatividad en las niñas y niños.
\end{abstract}

Educación, Desarrollo App, M-Learning

\begin{abstract}
Nowadays, girls and boys manage their own learning, therefore, learning is never as great as when a teacher is present, since it is in charge of mediating, transferring and translating each stimulus to girls and boys. This research highlights the general objective to develop a support tool for learning compression and reading for children of first grade of primary school General Lázaro Cárdenas de Tejupilco, State of Mexico. The methodology used is based on research "Apply in practice the lessons learned to achieve the transformation of the practice itself and that of the subjects of study". (Barabtarlo Y Zedansky, 2002). In conclusion, a positive result was achieved where the students were able to develop and improve Reading Comprehension, in addition that the stories not only promote access to the contents of the culture, knowledge, values, but also, put in motion important mechanisms linked to cognitive, linguistic and creativity development in girls and boys.
\end{abstract}

Education, Development App, M-Learning

Citación: PÉREZ-VÁZQUEZ, Jenner \& MENDOZA-ZUÑIGA, Armando. SisCuentos: Herramienta de apoyo para el aprendizaje de Compresión y Lectura para Niñas y Niños de Primer Grado de Primaria. Revista de Ciencias de la Educación. 2019. 3-10: 20-26

\footnotetext{
* Correspondencia del Autor (correo electrónico: jennerpv@ hotmail.com)

$\uparrow$ Investigador contribuyendo como primer autor.
} 


\section{Introducción}

En la actualidad la educación ha tenido un impacto evolutivo que afectan más y con mayor rapidez nuestra vida cotidiana, que van desde los avances en la ciencia, la tecnología, los sistemas sociales, políticos y económicos.

Las instituciones educativas tienen años desarrollando una educación tradicional, pero hoy se encuentra con discernimientos que objetan su proceder, con nuevas corrientes pedagógicas, introduciendo cambios y avances tecnológicos que impactan en mayor o menor medida a la práctica docente, y que deben mantenerse a la vanguardia en un mundo cada vez más competitivo.

En México existen dos tipos de evaluaciones sobre el logro de aprendizajes en la escuela. Las nacionales como el Plan Nacional para las Evaluaciones de los Aprendizajes (PLANEA) - y las internacionales — como el Estudios Regionales Comparativos y Explicativos (ERCE), de tipo regional, y el Programa Internacional de Evaluación de los Estudiantes (PISA), de tipo internacional. Ambas coinciden en señalar bajos resultados educativos e importantes brechas entre diversos grupos de población.

Los últimos resultados nacionales para primaria (2018) y secundaria (2017) señalan que, en educación primaria, $49.1 \%$ de estudiantes tiene resultados insuficientes en lenguaje y comunicación, y el $59.1 \%$ en matemáticas; en secundaria, el $33.8 \%$ de los estudiantes cuentan con resultados insuficientes en lenguaje y comunicación y el $64.5 \%$, en matemáticas.

En educación media superior, el 33.9\% de los estudiantes tiene resultados insuficientes en lenguaje y comunicación, y el $66.2 \%$ en matemáticas. (Instituto Nacional para la Evaluación de la Educación, 2018).

En lenguaje y comunicación, casi la mitad de las niñas y niños de primaria tienen dificultades para tareas con nivel alto de complejidad, como la comprensión de textos argumentativos y de opinión, y habilidades indispensables para el desarrollo del pensamiento crítico.
Los bajos resultados evidencian una vez más que la comprensión lectora es uno de los temas pendientes en el sistema educativo, es necesario recordar las principales características que hacen a la comprensión lectora uno de los desafíos más importantes de todo sistema educativo y de una sociedad de la información cada vez más exigente.

Según datos de la Organización para la Cooperación y el Desarrollo Económico (OCDE), la comprensión lectora entre los mexicanos está por debajo del promedio internacional. Estadísticas del Programa para la Evaluación Internacional de Alumnos (PISA), que analizan el desempeño de 540 mil estudiantes de 15 años en 72 países en el 2015, revelan que los mexicanos obtienen en promedio 423 puntos, 70 puntos por debajo del promedio.

El programa PISA, apunta hacia el desarrollo de una competencia lectora, es decir "la capacidad individual para comprender, utilizar y analizar textos escritos con el fin de lograr sus objetivos personales, desarrollar sus conocimientos y posibilidades y participar plenamente en la sociedad". ((OCDE), 2015)

En este contexto, las organizaciones educativas no pueden pasar por alto esta problemática; ya que el papel que desempeñan en la sociedad las convierte en el eje de su desarrollo y las compromete a una búsqueda constante de las estrategias, herramientas y recursos que contribuyan a construir el futuro que anhela nuestro país, lo que motiva con interés el estudio de esta problemática para contribuir y mejorar su aprendizaje y personalidad de las niñas y los niños desde un nivel de estudio de primer año de primaria, de esta manera se llevó a cabo la elaboración del presente proyecto, realizado en la Escuela General Lázaro Cárdenas de Tejupilco, Estado de México, con el objetivo de fomentar en las niñas y niños su comprensión lectora por medio del desarrollo de un Sistema Interactivo de Cuentos, y despertar la afición a la lectura, su habilidad para que construyan nuevos significados y entiendan lo escuchado o leído de una forma motivadora y atractiva.

En conclusión, se obtuvo un resultado positivo donde los estudiantes fueron capaces de desarrollar y mejorar la comprensión lectora. 


\section{Descripción del Método}

Las Tecnologías de la Información y Comunicación (TIC) son un hecho que evoluciona diariamente en la vida cotidiana de la sociedad.

En la actualidad la formación, de cualquier individuo, debe enfrentar el uso de las tecnologías como herramientas pedagógicas, con el fin de que se desarrollen estrategias que le sirvan para enfrentar y solucionar las necesidades de la sociedad presente y futura.

Las TIC's son herramientas que favorecen a las escuelas aportando material de apoyo a las instituciones que no cuentan con una biblioteca multidisciplinaria, ni material didáctico adecuado, las tecnologías es la innovación educativa del momento que permiten a los docentes y alumnos entrar en un mundo nuevo lleno de información, lo que facilitan el ambiente de aprendizaje, desarrollando capacidad de entendimiento, de la lógica y favorece el proceso de enseñanza aprendizaje, que se adapta a nuevas estrategias que permiten el desarrollo cognitivo creativo y divertido en las áreas tradicionales del sistema educativo.

El psicopedagogo Vigotsky da una aplicación fundamental que atañe al concepto de educación, que se refiere al proceso de controlar los elementos de la tarea que están lejos de las capacidades del estudiante, de manera que pueda concentrarse en dominar los que puedan captar con rapidez, en el ámbito del aprendizaje, al comienzo el docente realiza la mayor parte del quehacer, pero después, hace partícipe a los alumnos delegando responsabilidad. (MOLL, 1993).

Por lo tanto, nunca es el aprendizaje tan grande como cuando un docente está presente, ya que es el encargado de mediar, trasladar y traducir cada estímulo a las niñas y niños.

La metodología utilizada está basada en la investigación "Aplicar en la práctica los aprendizajes logrados para conseguir la trasformación de la práctica misma y la de los sujetos motivos de estudio". (Barabtarlo Y Zedansky, 2002).
Para Kemmis, Stephen / Mctaggart, Robin la investigación-acción es: "una forma de indagación autoreflexiva realizada por quienes participan (profesorado, alumnado, o dirección, por ejemplo) en las situaciones sociales (incluyendo las educativas) para mejorar la racionalidad y la justicia de: a) sus propias prácticas sociales o educativas; b) su comprensión sobre las mismas; y c) las situaciones e instituciones en que estas prácticas se realizan (aulas o escuelas, por ejemplo)". (KEMMIS, 1988). Ver figura 1.

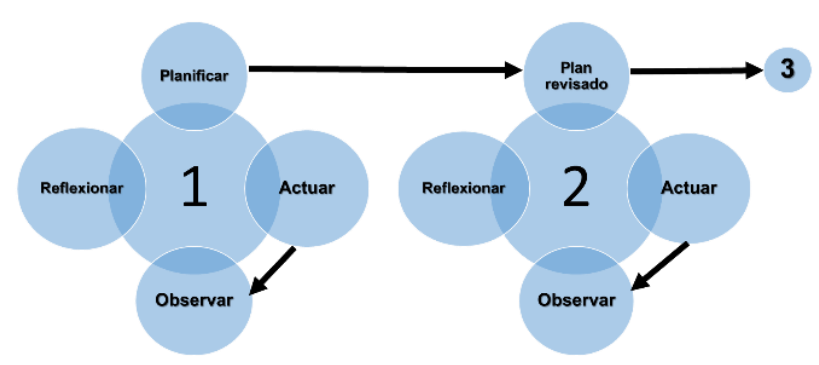

Figura 1 Espiral de ciclos de la IA

Con el presente proyecto se hace un aporte significativo al avance de la Institución en la utilización de las Tecnologías de la Información y la comunicación, además de contribuir con la solución del problema planteado. Los cuentos siempre están presentes en el salón de clase, así inconscientemente nos encontramos rodeados de los elementos a trabajar en este proyecto y aprovechamos cada momento para recordar los contenidos que queremos afianzar.

El cuento bajo todas sus formas facilita la adquisición del desarrollo personal y social, como también del lenguaje. Para Víctor Montoya el cuento es: "la narración de algo acontecido o imaginado", y señala también que en el cuento tanto el trasmisor como el receptor saben que es una ficción que toma como base la realidad. (Montoya, 2002).

Los cuentos cumplen con una importante función educativa al mismo tiempo que inician al alumnado en el placer de la lectura. El cuento es una forma particular de narración cuyo contenido suele ser distinto del contenido de otro tipo de discursos. Detenta una estructura diferente de la descripción y la exposición. Posee tramas, personajes que interactúan colectivamente, y tramas; puede tener una visión interna, variar el punto de vista y abraza prefiguraciones. Por ello utilizaremos como estrategia motivadora: el cuento. 
Además, la lectura de un cuento permite la realización de un amplio abanico de actividades diferentes para el desarrollo integral del niño y la niña, algo que, como docentes, debemos saber aprovechar. La actividad de leer o narrar el cuento transmite unos valores educativos que el relato lleva implícito como son la generosidad, la amistad, la paciencia, el respeto o la superación.

El tipo de cuento que tomaremos para el proyecto será el cuento infantil que se estructura con 3 categorías formales básicas: Ver figura 2 .

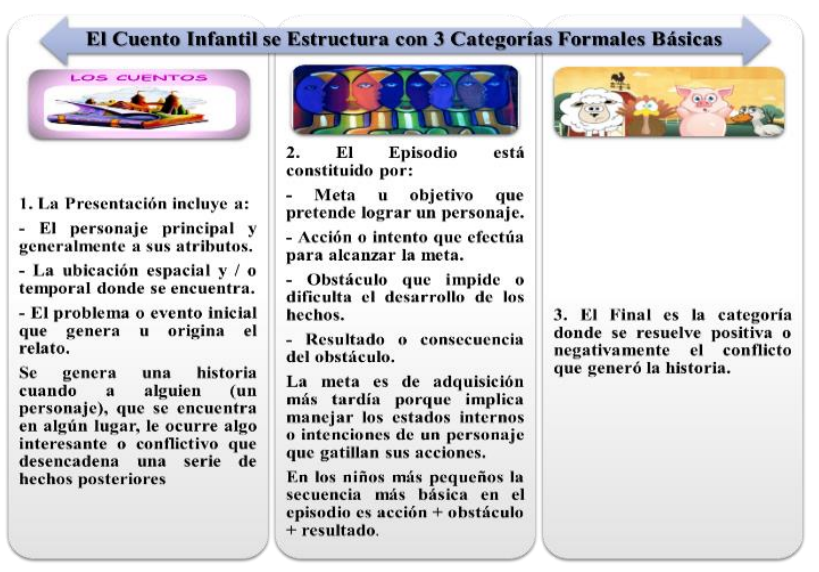

Figura 2 El Cuento Infantil se Estructura con 3 Categorías Formales Básicas

Para realizar cualquier actividad de enseñanza-aprendizaje se tendrá en cuenta las características propias de las niñas y niños de estas edades, así como sus conocimientos previos y sus niveles de desarrollo. También es necesario que se ofrezca una gran riqueza de estímulos para atender a sus necesidades e intereses a la vez que les ayude a desarrollar la comprensión lectora y actitudes que se desea potenciar en ellos.

Las actividades que pueden realizarse a partir de la lectura de un cuento, son las siguientes: ver figura 3 .

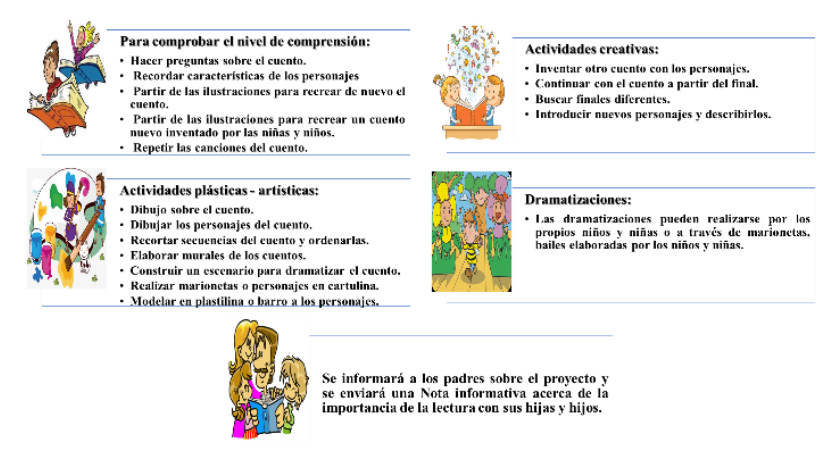

Figura 3 Estrategia aplicada a partir de la lectura de un cuento en el sitio web

ISSN: 2523-2436

ECORFAN® Todos los derechos reservados
Se recurrirá, como otra forma de motivación a las actividades lúdicas que para fomentar tanto la participación como la cooperación, gracias a la realización de actividades grupales.

El docente será una figura de ayuda, orientación y guía para las niñas y niños. Además, tendrá que establecer una relación positiva que favorezca el desarrollo normal de la clase.

El sistema interactivo de cuentos que se diseña e implementa a través de esta investigación, es una herramienta educativa que sirve de apoyo que facilite al docente dar clases interactivas y el resultado en el aprendizaje (comprensión lectora) sean satisfactorios para niñas/niños/docente.

\section{Arquitectura del Sistema de Información}

Dentro de lo que es la definición de la arquitectura del sistema de información se opta por manejar lo que se llama el modelo de n capas o niveles. (Modelo n- Three Tier) para entornos computacionales. (Tier, 2003).

La razón para esta decisión se basa en lo siguiente: La tecnología denominada n Capas es utilizada principalmente por todas las aplicaciones de Internet/Intranet:

Un servidor es una computadora remota - en algún lugar de la red - que proporciona información según una petición

- Un cliente funciona en una computadora local, que se comunica con el servidor remoto, y pide a éste la información.

- $\quad$ El servidor envía la información solicitada.

En este caso, se tiene que el sistema de información estará dividido en: datos (base de datos), la lógica de negocio y presentación o interfaz gráfica del usuario. La Capa de datos es donde radican los datos y es la encargada de acceder a los mismos. Está integrado por uno o más gestores de bases de datos que tiene como función el almacenamiento de datos, reciben solicitudes de almacenamiento o recuperación de información desde la capa de negocio. En la capa de la lógica del negocio se modela el comportamiento del sistema, basándose en los datos provistos por la capa de datos, y actualizándolos según sea necesario, se comunica con la capa de presentación, para recibir las solicitudes y presentar los resultados.

PÉREZ-VÁZQUEZ, Jenner \& MENDOZA-ZUÑIGA, Armando. SisCuentos: Herramienta de apoyo para el aprendizaje de Compresión y Lectura para Niñas y Niños de Primer Grado de Primaria. Revista de Ciencias de la Educación. 2019 
Esta capa describe los distintos procesos de negocio que tienen lugar en lo que se refiere a la evaluación, aplicación y elaboración de pruebas de tamizaje para los alumnos.

Finalmente, la capa de presentación contiene todos los elementos que constituyen la interfaz con el usuario. Esta capa incluye todo aquello con lo que el usuario puede interactuar. De acuerdo con esto, en la Figura 4, se muestra el Diagrama de Arquitectura del Sistema de Información del presente proyecto.

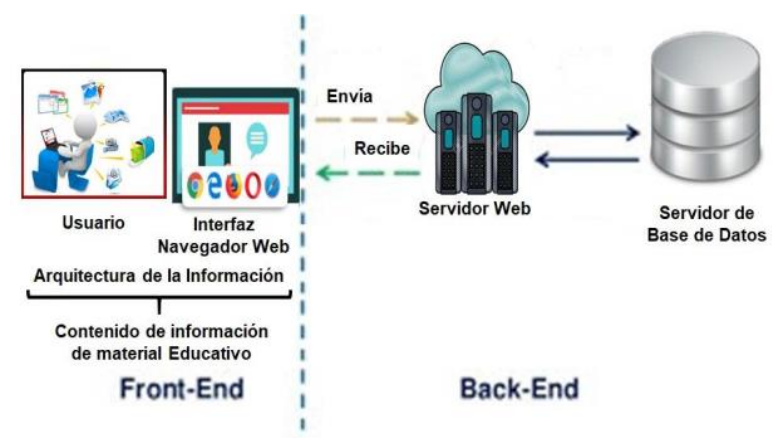

Figura 4 Arquitectura del Sistema Computacional

\section{El Diseño de Pantallas}

El presente Sistema Interactivo de Cuentos nos ayudara a entender la funcionalidad del menú principal ubicado en la parte central del sitio web donde se encuentra publicados los contenidos y los Cuentos Lectura, Cuentos Audio y Juegos Dinámicos, la navegabilidad del Peque Cuentos es fácil rápida y sencillo. Figura 5.

El Sistema Interactivo de Cuentos está dado por hipertextos en donde el usuario puede desplazarse libremente en cualquier dirección. Los enlaces son palabras claves y botones. Al accionarlos o al hacer una indicación con el puntero del ratón, la página indicada aparece en pantalla, y un nuevo texto se despliega ante nuestra pantalla, ocultando otros textos.

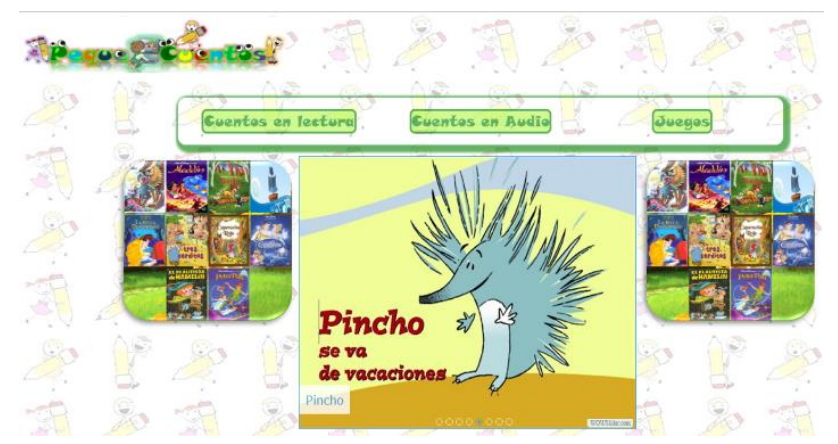

Figura 5 Interfaz de la página Inicio de la aplicación educativa
En la sección Cuentos de Lectura el texto es bastante claro, el tamaño de la letra es adecuado en todas las páginas, los contrastes de colores entre el fondo y el texto son apropiados y no distorsionan la lectura.

Dentro del espacio del Sistema Interactivo de Cuentos: Peque Cuentos se encuentra la participación de los personajes de los cuentos en los contenidos correspondientes dándole una identidad grafica visual.

El usuario puede avanzar y retroceder para la interacción con el cuento en proceso de lectura.

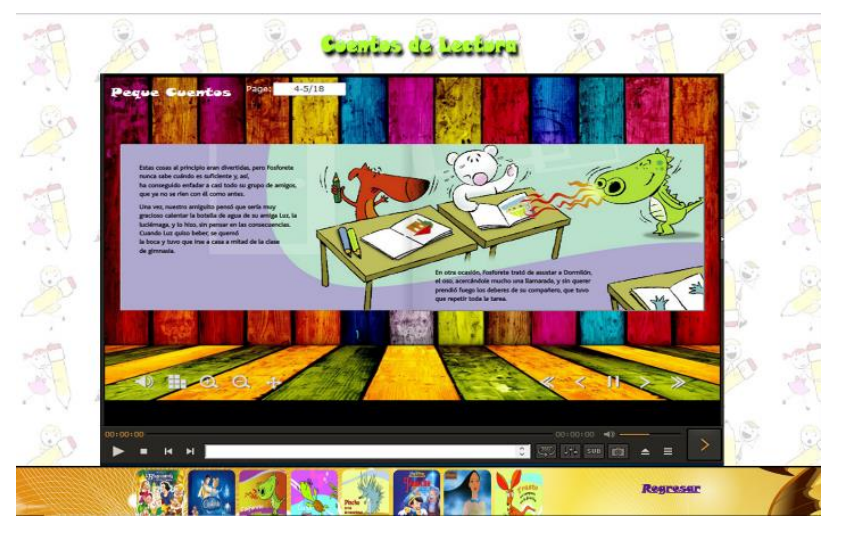

Figura 6 Interfaz gráfica cuentos de lectura

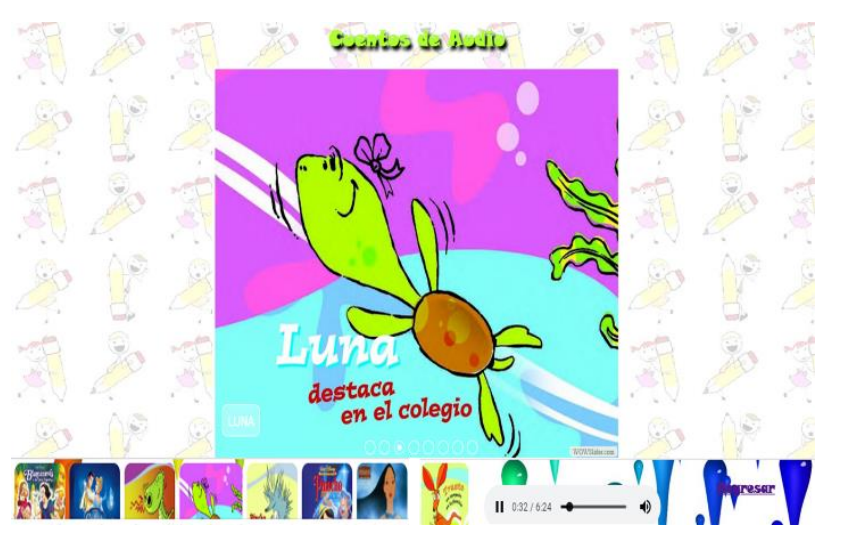

Figura 7 Interfaz gráfica cuentos de audio

Con lo que respecta a la sección de Cuentos en Audio los cuentos son muy interactivos e ilustrados acompañados de textos, movimiento en la imagen y sonidos que narran la historia y música de fondo para niños al usuario también le permiten interactuar con la historia participando en la narración.

Las multimedias del Sistema Interactivo de Cuentos en la sección de juego tiene muchas imágenes ilustradas, poseen sonido, el usuario (niñas/niños) pueden interactuar con variados juegos de destreza. Ver figura 8.

PÉREZ-VÁZQUEZ, Jenner \& MENDOZA-ZUÑIGA, Armando. SisCuentos: Herramienta de apoyo para el aprendizaje de Compresión y Lectura para Niñas y Niños de Primer Grado de Primaria. Revista de Ciencias de la Educación. 2019 
El hecho de jugar es en sí mismo un proceso tremendamente creativo que fomenta la imaginación, el pensamiento original, la resolución de problemas, el pensamiento crítico y la autorregulación. El Sistema Interactivo de Cuentos busca permitir a las niñas y niños de esta escuela acceso a materiales educativos que sirvan para estimular y orientar el aprendizaje educativo, potenciando la experiencia sensorial y facilitar la adquisición del aprendizaje. Técnicas de recolección de la información. Para la validación de este proyecto se empleó como técnica de recolección de información, de entrevista directa y la encuesta, que fue aplicada a profesores, estudiantes y padres de familia en la Institución.

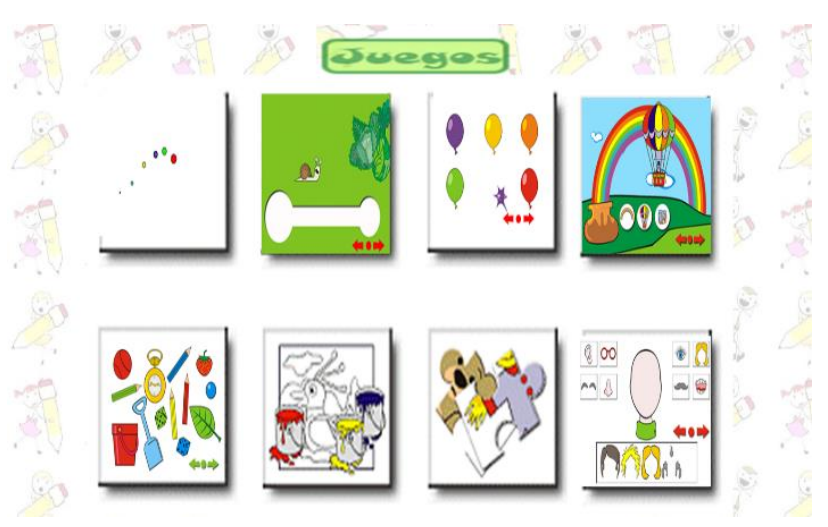

Figura 8 Interfaz gráfica juegos didácticos

\section{Resumen de resultados}

La educación formal en pocas ocasiones se encarga de enseñar la comprensión en la lectura, más bien la hace funcionar como un requerimiento que se le programa al estudiante, el deber comprender y el deber entender.

Este proyecto pretende, desarrollar y mejorar la comprensión lectora, promover la lectura y el gusto por la literatura infantil dentro y fuera del aula. Además, no podemos eludir el potencial de los cuentos como herramienta para emprender muchos aspectos con los niños: emociones, valores, diferentes situaciones que se pueden trasladar a la vida. Los criterios de autoevaluación propuestos al estar trabajando con el Sistema interactivo de cuentos y que fueron desarrollados por cada docente con su grupo de niñas y niños en los salones de clase son los siguientes:

\footnotetext{
- Muestra interés por aprender y se ha interesado la niña/niño por el tema propuesto Ha participado activamente en las actividades y nombra y reconoce el vocabulario básico del cuento.
}

\section{- Identifica la idea principal, reconocer y recordar hechos y detalles del cuento.}

El instrumento de evaluación que se utilizo fue la observación, para obtener información directa sobre el comportamiento de las niñas y niños. Se evaluó a través de una tabla que se cataloga si lo ha conseguido, no lo ha conseguido o en proceso y observaciones en la que anotaremos aquellos que nos ha llamado la atención del criterio a evaluar. Hay que tener en cuenta que algunas niñas y niños tardan más tiempo en adquirir estos contenidos.

La sensación que detenta este Sistema interactivo de cuentos fue aceptable en las diferentes pruebas realizadas, las encuestas aplicadas a las personas involucradas muestran buenos resultados categorizándola como un Sistema que da resultados como herramienta introductoria a la comprensión lectora de las niñas y niños.

Se ofrece información de forma amena, con dibujos, imágenes y ejemplos claros que sirven de estímulo y apoyo a las niñas y niños, al igual que navegar con facilidad. Tiene conceptos y ejemplos que permiten una mayor comprensión de los elementos de aprendizaje, basados en el plan de trabajo del nivel educativo para el que fue desarrollado.

\section{Conclusiones}

- Es imprescindible fomentar el aprendizaje de la comprensión lectora, a través de estrategias significativas, para motivar la imaginación, la creatividad, y la dinámica para desarrollar la competencia de análisis y comprensión, es labor esencial de todo docente en cualquier área o nivel académico en que se desempeñe.

- Los aspectos de comunicación y reflexión van de la mano, ya que lo que se exterioriza se profundiza, y fructifica.

- $\quad$ Se constató que era viable de aplicar por que durante la realización del diagnóstico se observó que los docentes estaban motivados por participar en la etapa de presentación del tema, así como la disposición del personal directivo para su aplicación dentro de la institución. 
- Las estrategias aplicadas han sido recibidas con gran interés en las niñas y niños quienes han evidenciado cambios activos en cuanto a la participación, el compartir, el intercambio de ideas y la ayuda mutua; se llevó a cabo un aprendizaje cooperativo

- La integración de los cuentos como materiales educativos a través del Sistema Interactivo de Cuentos dentro del salón de clases tendrá una trascendencia y resultados diferentes según cual sea el plan que guie la acción del docente al incorporar este nuevo instrumento de apoyo de aprendizaje tecnológico.

Al desarrollarse el Sistema Interactivo Cuentos se logró construir una herramienta de acceso gratuito, conformada por recursos didáctico, además que los cuentos no sólo promueven el acceso a los contenidos de la cultura, los conocimientos, los valores, sino que, ponen en movimiento importantes mecanismos vinculados con el desarrollo cognitivo, el lingüístico y la creatividad en las niñas y niños.

A manera de conclusión se eleboro una herramienta de desarrollo Web para apoyo Didactico de primer grado de primaria, adaptable a los programas de estudios del nivel Basico de la SEP.

\section{Recomendaciones}

Como recomendación para favorecer con esta tarea el docente debe mantenerse en constante preparación, para adquirir las herramientas necesarias que contribuyan como beneficio que se reflejen en la educación de los alumnos.

Realizar una aplicación móvil con la finalidad de poder ser utilizado en diferentes sistemas de smarphone.

\section{Referencias}

(OCDE), O. p. (2015). Estadísticas del Programa para la Evaluación Internacional de Alumnos (PISA) 2015 - Resultador. México: OCDE.
Barabtarlo Y Zedansky, A. (2002). La epistologia de la investigación - acción, Proyectos de innovación. México: ED CASTELLANOS (ES), Purrua.

Instituto Nacional para la Evaluación de la Educación, (. (2018). Políticas para mejorar el aprendizaje de los estudiantes en México. Ciudad de México: INEE.

KEMMIS, S. /. (1988). CÓMO PLANIFICAR LA INVESTIGACIÓN-ACCIÓN. España: Laertes Editorial.

MOLL, L. C. (1993). Vygotsky y la educación : connotaciones y aplicaciones de la psicología sociohistórica en la educación. Buenos Aires.: Aique.

Montoya, V. (2002). El origen de los cuentos. Sincronía - Revista electrónica de Filosofía, Letras y Humanidades.

Tier, E. M. (2003). Lagash System. El modelo de tres capas o "Three Tier". Obtenido de http://www.lagash.com/papers/paper_threetier.h tml 